\title{
Impact of alkali and heat pretreatment on the pathway of hydrogen production from sewage sludge
}

\author{
WEI SuZhen, XIAO BenYi \& LIU JunXin* \\ Research Center for Eco-Environmental Sciences, Chinese Academy of Sciences, Beijing 100085, China
}

Received March 30, 2009; accepted July 29, 2009

\begin{abstract}
Due to the presence of various types of hydrogen-producing bacteria and numerous organics such as protein and carbohydrate, sewage sludge is a potential material for biological hydrogen production. In this study, two batch tests were carried out to investigate the impact of alkali and heat pretreatment on the pathway of hydrogen production from sewage sludge. The results showed that the heat treatment had a stronger lethal effect on bacteria than the alkali treatment, and could effectively kill hydrogen-consuming bacteria. The heat treatment was more suitable for enriching acidophilic hydrogen-producing bacteria, while the alkali treatment was more suitable for enriching basophilic hydrogen-producing bacteria. A maximum hydrogen production of $10.32 \mathrm{~mL} / \mathrm{g}$-COD from alkali pretreated sludge was obtained at an initial $\mathrm{pH}$ of 11; while a maximum hydrogen production of $8.94 \mathrm{~mL} / \mathrm{g}$-COD from heat pretreated sludge was obtained at an initial $\mathrm{pH}$ of 5 . Hydrogen production in alkali conditions ( $\mathrm{pH}>9$ ) from alkali pretreated sludge mainly depended on the fermentation of protein by protein-utilizing bacteria; whereas hydrogen production in acidic conditions $(\mathrm{pH}<6)$ from heat pretreated sludge mainly depended on the fermentation of carbohydrate by glucose-utilizing bacteria.
\end{abstract}

sewage sludge, alkali pretreatment, heat pretreatment, hydrogen production

Citation: Wei S Z, Xiao B Y, Liu J X. Impact of alkali and heat pretreatment on the pathway of hydrogen production from sewage sludge. Chinese Sci Bull, 2010, 55: 777-786, doi: 10.1007/s11434-009-0591-7

Sewage sludge in wastewater treatment is a special type of organic waste, consisting of a variety of microbial cells, some refractory organics and inorganics. Among the various sludge disposal routes, anaerobic digestion plays an important role due to its ability to further transform organic matter into biogas, reduce the amount of final sludge solids and destroy most of the pathogens present in the sludge [1]. Hydrogen gas, an attractive energy carrier for replacing conventional fossil fuel in the future due to its cleanness and high energy yield $\left(142.35 \mathrm{~kJ} \mathrm{~g}^{-1}\right)$, is an important intermediate product in the anaerobic digestion process, and is consumed by hydrogen-utilizing methanogens to reduce carbon dioxide to methane [2]. Recent studies have focused on using sewage sludge to produce hydrogen gas. However, since most of the organics in sludge are in microbial cells

*Corresponding author (email: jxliu@ rcees.ac.cn) and the rigid structure of microbial walls prevent the inner cell products from leaking out, sewage sludge must undergo treatment before being used for hydrogen production [3]. Methods for pretreating sludge include mechanical pretreatment [4], ultrasonic disintegration [5], alkali pretreatment [6], heating pretreatment [7] and thermochemical pretreatments [8]. This latter treatment usually involves heating and alkali pretreatment prior to hydrogen production from sludge. In addition, there are various types of activated microorganisms in sewage sludge, including hydrogen-producing bacteria, hydrogen-consuming bacteria and pathogens. Following pretreatment, not only can the organic materials be released from the sludge cells [9-11], but the hydrogen-producing bacteria can also be screened [12-17]. Thereby, the treated sludge is a potential resource for producing hydrogen.

However, the hydrogen yield and the character of hy- 
drogen production are different with different pretreatment methods. For example, compared with alkali treatment, heat treatment can completely suppress the activity of methanogens [18]. Mu et al. [19] stated that hydrogen production from glucose by heat-treated seed sludge was much higher than that by alkali-treated seed sludge. However, in another experiment using dairy wastewater, heat pretreated sludge obtained a very low hydrogen yield [20]. Cai et al. [21] found that a high hydrogen yield could be obtained from alkali pre-treated sludge under an initial alkali $\mathrm{pH}$ of 11, where the maximum hydrogen yield was $16.90 \mathrm{~mL} \mathrm{H}_{2} / \mathrm{g}$-DS (dry solids), and was only $2.90 \mathrm{~mL} \mathrm{H}_{2} / \mathrm{g}$-DS under weakly acidic conditions ( $\mathrm{pH}$ 6). Xiao and Liu [22] indicated that sterilization pretreatment could increase the hydrogen yield from $0.35 \mathrm{~mL} \mathrm{H}_{2} / \mathrm{g}$-VS (volatile solid, raw sludge) to 16.26 $\mathrm{mL} \mathrm{H}_{2} / \mathrm{g}$-VS (sterilized sludge) under near neutral $\mathrm{pH}$ conditions. These reports indicate that the effect of different pretreatments on hydrogen production from sludge is different, but the reason for this is unclear at present. The purpose of this study is thus to investigate the influence of heating and alkali pretreatment on enriching hydrogen-producing bacteria and on the pathway of hydrogen production.

\section{Materials and methods}

\subsection{Pretreatment of sludge}

The sewage sludge used in this study was taken from a municipal wastewater treatment plant in Beijing, which handles $300000 \mathrm{~m}^{3} / \mathrm{d}$ of wastewater. The sludge was first concentrated by sedimentation for about $4 \mathrm{~h}$, and then underwent the following heating and alkali pretreatments. The characteristics of the sludge before and after pre-treatment are listed in Table 1.

(i) Alkali pre-treatment. According to the method of Cai et al. [21], the concentrated sludge was added slowly to $4 \mathrm{M}(1 \mathrm{M}=1 \mathrm{~mol} / \mathrm{L})$ sodium hydroxide with stirring and the $\mathrm{pH}$ was controlled at 12.0. After stirring for $30 \mathrm{~min}$, the sludge was left for $24 \mathrm{~h}$. The supernate of alkali pre-treated sludge (SAPS) was obtained by centrifuging the treated sludge at $4000 \mathrm{r} / \mathrm{min}$ for $15 \mathrm{~min}$ and was used as the hydrogen-producing medium. The centrifuged sludge was used as alkali pretreated seed sludge (APSS).

(ii) Heating pre-treatment. (1) one of the concentrated sludge samples was heated at $100^{\circ} \mathrm{C}$ for $15 \mathrm{~min}$, and then cooled to room temperature, and this was used as heat pretreated seed sludge (HPSS); (2) another concentrated sludge sample was heated at $121^{\circ} \mathrm{C}$ for $30 \mathrm{~min}$, then cooled to room temperature and its supernate of heat pre-treated sludge (SHPS), which was obtained by centrifuging the treated sludge at $4000 \mathrm{r} / \mathrm{min}$ for $15 \mathrm{~min}$, was used as the hydrogen-producing medium [23].

\subsection{Hydrogen-producing medium}

In order to investigate the influence of soluble organics released from the sludge on hydrogen production, the supernate of the pretreated sludge, SAPS and SHPS, was used as the substrate instead of the whole treated sludge, because the subsequent process of $\mathrm{pH}$ adjustment and sterilization might re-release organic material from the sludge cells. An artificial medium was prepared using peptone $(10 \mathrm{~g} / \mathrm{L})$ or glucose $(10 \mathrm{~g} / \mathrm{L})$ as the sole organic carbon substrate, plus the following nutrients (in $\mathrm{mg} / \mathrm{L}$ ): $\mathrm{NaCl}, 1000 ; \mathrm{NH}_{4} \mathrm{Cl}$, 2000; $\mathrm{MgCl}_{2} \cdot 6 \mathrm{H}_{2} \mathrm{O}, 100 ; \mathrm{FeSO}_{4} \cdot 7 \mathrm{H}_{2} \mathrm{O}, 90 ; \mathrm{CaCl}_{2}, 80$; $\mathrm{K}_{2} \mathrm{HPO}_{4} \cdot 3 \mathrm{H}_{2} \mathrm{O}, 100 ; \mathrm{MnCl}_{2} \cdot 4 \mathrm{H}_{2} \mathrm{O}, 0.2 ; \mathrm{Na}_{2} \mathrm{MoO}_{4} \cdot 2 \mathrm{H}_{2} \mathrm{O}$, $0.1 ; \mathrm{CoCl}_{2} \cdot 6 \mathrm{H}_{2} \mathrm{O}, 0.08 ; \mathrm{ZnCl}_{2}, 0.8 ; \mathrm{CuCl}_{2} \cdot 2 \mathrm{H}_{2} \mathrm{O}, 0.4$ and $\mathrm{H}_{3} \mathrm{BO}_{3}, 0.1$. The hydrogen-producing media were sterilized at $115^{\circ} \mathrm{C}$ for $30 \mathrm{~min}$ before being inoculated with seed bacteria.

\subsection{Hydrogen production tests}

Two batch tests were carried out in this study. For the first batch, $1 \mathrm{~mL}$ pretreated seed sludge, HPSS or APSS, and $149 \mathrm{~mL}$ sterile SHPS or SAPS were added into each bottle, and the $\mathrm{pH}$ values were adjusted to 5, 6, 8, 9, 10 and 11 with hydrochloric acid and sodium hydroxide, respectively. For

Table 1 Characteristics of the sewage sludge used in this study ${ }^{a)}$

\begin{tabular}{|c|c|c|c|c|c|}
\hline Item & Raw sludge & Alkali pretreated sludge & Heat pretreated sludge & SAPS & SHPS \\
\hline $\mathrm{pH}$ & 7.1 & 11.4 & 6.9 & 11.4 & 6.9 \\
\hline $\mathrm{SCOD}(\mathrm{mg} / \mathrm{L})$ & 107 & 3574 & 2112 & 3574 & 2112 \\
\hline TCOD (mg/L) & 12624 & 12624 & 12624 & 4668 & 3129 \\
\hline VSS (g/L) & 6.78 & - & - & - & - \\
\hline TSS $(g / L)$ & 9.87 & - & - & - & - \\
\hline Soluble carbohydrate $(\mathrm{mg} / \mathrm{L})$ & 17.1 & 344 & 280 & 344 & 280 \\
\hline Soluble protein $(\mathrm{mg} / \mathrm{L})$ & 20.1 & 2144 & 1276 & 2144 & 1276 \\
\hline Carbohydrate/protein & 0.85 & 0.16 & 0.22 & 0.16 & 0.22 \\
\hline
\end{tabular}

a) SAPS, Supernate of alkali pretreated sludge; SHPS, supernate of heat pretreated sludge 
the second batch, the fermentation liquid of the first batch, which was cultivated up to the end of the experiment when biogas generation stopped, was used as the seed bacteria. 1 $\mathrm{mL}$ fermentation liquid and $149 \mathrm{~mL}$ sterile peptone or glucose medium was added into each bottle, and the $\mathrm{pH}$ values were adjusted to 5.5 and 10.5 with hydrochloric acid and sodium hydroxide, respectively. The test bottles were then flushed with nitrogen gas to provide an anaerobic environment. All the fermentation tests were conducted in $300 \mathrm{~mL}$ vitreous bottles at $37^{\circ} \mathrm{C}$. Each fermentation test was repeated twice.

\subsection{Analytical methods}

The volume of biogas produced in each bottle was periodically measured using a wet glass syringe $(10 \mathrm{~mL}$ or $20 \mathrm{~mL}$ volume). The hydrogen concentration in the headspace of the vessels was determined by a gas chromatograph (GC122, China.) equipped with a thermal conductivity detector and a 6 m stainless-steel column packed with Porapak Q (80-100 mesh). The temperatures of the injector, detector and column were maintained at 140,140 and $80^{\circ} \mathrm{C}$, respectively. Nitrogen was used as the carrier gas at a flow rate of 30 $\mathrm{mL} / \mathrm{min}$. Hydrogen gas production was calculated from the bottle headspace measurements of gas composition and the total volume of biogas produced at each time interval using the following equation:

$$
V_{H, i}=V_{H, i-1}+C_{H, i}\left(V_{G, i}-V_{G, i-1}\right)+V_{H}\left(C_{H, i}-C_{H, i-1}\right),
$$

where $V_{H, i}$ and $V_{H, i-1}$ represents the cumulative hydrogen gas volumes at the current $(i)$ and previous $(i-1)$ time intervals, $V_{G, \mathrm{i}}$ and $V_{G, i-1}$ represents the total biogas volumes in the current and previous time intervals, $C_{H, i}$ and $C_{H, i-1}$ represents the fraction of hydrogen gas in the headspace of the bottle measured using gas chromatography in the current and previous time intervals, and $V_{H}$ denotes the total volume of headspace in the reactor [24].

The concentrations of soluble chemical oxygen demand (SCOD), protein, carbohydrate, volatile fatty acids (VFA) and ethanol were measured after the liquid samples were filtered using a $0.45-\mu \mathrm{m}$ membrane. The VFAs and ethanol were detected by another gas chromatograph (Agilent GC6890N, USA) equipped with a flame ionization detector and a $30 \mathrm{~m} \times 0.32 \mathrm{~mm}$ I.D. $\times 0.50 \mu \mathrm{m}$ capillary column (DB-FFAP, Agilent) using an adaptation procedure described by Liu and Logan [25]. Protein concentration was determined by Lowry's method using bovine albumin as the standard [26]. Carbohydrate concentration was measured by the phenol sulfuric acid method using glucose as the standard [27]. Total chemical oxygen demand (TCOD), SCOD, total suspended solids (TSS) and volatile suspended solids (VSS) were analyzed according to the standard method [28]. The $\mathrm{pH}$ was measured by a $\mathrm{pH}$ meter (PHS-3C, China).

\subsection{PCR-DGGE analysis}

After DNA was extracted from $10 \mathrm{~mL}$ zymotic liquid (which was taken at the end of the experiment when biogas generation had stopped) using the alkaline lysis method [29], the 16S rDNA genes (V3 to V5 region) were amplified using polymerase chain reactions (PCR). The universal primers were F338 (5' ACTCC TACGG GAGGC GCAG 3') and R804 (5' CTACC AGGGT ATCTA ATCC 3'). For the DGGE analysis, a GC clump (CGCCC GCCGC GCCCC GCGCC CGTCC CGCCG CCCCC) was added on the 5' end of F338. The PCR was run on a PTC100 thermocycler (MJ Research, Inc., USA). After detecting by $1.0 \%$ agarose gel electrophoresis, the PCR products were loaded onto a polyacrylamide gel $(6 \% \mathrm{wt} / \mathrm{vol})$ with a denaturant gradient ranging from $20 \%$ to $50 \%$. The DGGE electrophoresis was performed at $120 \mathrm{~V}$ for $8 \mathrm{~h}$ in $1 \times$ TAE buffer $(40 \mathrm{mM}$ Tris-acetate, $1 \mathrm{mM}$ EDTA, $\mathrm{pH} 8.0$ ) at a constant temperature of $60^{\circ} \mathrm{C}$ using a DCode ${ }^{\mathrm{TM}}$ Universal Mutation Detection System (Bio-Rad, USA) according to the method of Muyzer et al. [30]. After the runs, gels were stained with silver nitrate according to the method of Heukeshoven and Dernick [31]. Analysis of the DGGE gels was performed with Bio-Rad software Quantity One 4.6.2. DGGE fingerprints were automatically scored by the presence or absence of co-migrating bands, independent of intensity. Homology between sample banding patterns were quantified using the Dice index $(C)$ as: $C=2 j /(a+b)$, where $j$ is the number of bands common to samples $\mathrm{A}$ and $\mathrm{B}$, and $a$ and $b$ are the number of bands in samples $A$ and $B$, respectively $[32,33]$. This index ranges from 0 (no common bands) to 1 (identical band patterns). Cluster analysis based on the values of Dice coefficients was performed using the Pearson correlation and was done by UPGMA (unweighted pair-group method with arithmetic averages, also known as average linkage).

\subsection{Hydrogen production parameter analysis}

The cumulative hydrogen production volume during the tests was fitted with the modified Gompertz equation [34, 35]:

$$
H(t)=H_{\max } \exp \left\{-\exp \left[\frac{R_{\mathrm{m}} \times e}{H_{\text {max }}}(\lambda-t)+1\right]\right\},
$$

where $H(t)(\mathrm{mL})$ is the cumulative hydrogen produced at time $t, H_{\max }(\mathrm{mL})$ the maximum cumulative hydrogen production, $R_{\mathrm{m}}(\mathrm{mL} / \mathrm{h})$ the maximum hydrogen production rate, $\lambda(h)$ the lag phase. The values of $H_{\max }, R_{\mathrm{m}}$ and $\lambda$ for each batch were determined by best fitting the hydrogen production data for eq. (2) using the software Matlab 6.5 (Math Works Inc., Copyright 2001-2002) [23, 36]. In this study, the specific maximum hydrogen production rates $\left(R_{\mathrm{m}}\right)$ and the maximal cumulative hydrogen production $\left(H_{\max }\right)$ are expressed as $\mathrm{mL} / \mathrm{h}$ g-COD and $\mathrm{mL} / \mathrm{g}-\mathrm{COD}$, respectively. 


\section{Results and discussion}

\subsection{The first batch tests with the supernate of pre-treated sludge}

The time courses and kinetic parameters of hydrogen production from the supernate of pretreated sludge are illustrated in Figure 1 and Table 2, respectively. The results showed that irrespective of whether SHPS or SAPS was used as the substrate for hydrogen production, the specific maximum hydrogen production rates $\left(R_{\mathrm{m}}\right)$ and the maximal cumulative hydrogen production $\left(H_{\max }\right)$ of HPSS increased with decreasing initial $\mathrm{pH}$ from 9 to 5 , and both the highest $R_{\mathrm{m}}$ of $0.80 \mathrm{~mL} / \mathrm{h}$ g-COD and the maximum $H_{\max }$ of 8.94 $\mathrm{mL} / \mathrm{g}-\mathrm{COD}$ were obtained from SHPS at an initial $\mathrm{pH}$ of 5 . However, irrespective of whether SHPS or SAPS was used as the substrate, the $H_{\max }$ of APSS increased with the increasing initial $\mathrm{pH}$ and the maximum $H_{\max }$ of 10.32 $\mathrm{mL} / \mathrm{g}-\mathrm{COD}$ was obtained from SAPS at an initial $\mathrm{pH}$ of 11 . The $R_{\mathrm{m}}$ of APPS displayed the same trend when SAPS was used as the substrate and the highest $R_{\mathrm{m}}$ of $0.89 \mathrm{~mL} / \mathrm{h} \mathrm{g}$ COD was obtained at an initial $\mathrm{pH}$ of 10 , however, when SHPS was used as the substrate, the $R_{\mathrm{m}}$ of APPS in- creased with the decreasing initial $\mathrm{pH}$ (11 to 5). Furthermore, under alkali conditions ( $\mathrm{pH} 8-11$ ), the $R_{\mathrm{m}}$ and $H_{\max }$ of APPS from SAPS were higher than those from SHPS, whereas under acidic conditions ( $\mathrm{pH} 5-6)$, the $R_{\mathrm{m}}$ and $H_{\max }$ of APPS from SAPS were lower than those from SHPS, respectively. According to the experimental results in Table 2 , irrespective of whether SHPS or SAPS was used as the substrate for hydrogen production, the lag phase of HPSS as inoculants was much longer than that of APSS. Under the same initial pH condition, the lag phase of SHPS was similar to that of SAPS. Therefore, the initial $\mathrm{pH}$ and microorganisms were the main factors affecting the lag phase of hydrogen production, and not the soluble organic materials.

These results indicated that a weakly acidic condition was advantageous for hydrogen production from SHPS using HPSS as inoculants, while an alkali condition was favorable for hydrogen production from SAPS using APSS as inoculants. After reaching the peak of hydrogen production, the hydrogen produced by APSS was consumed, but the hydrogen produced by HPSS was not consumed even after a long time period (Figure 1). Therefore, it was suggested that the hydrogen-producing bacteria in the heat and alkali treatments were different. Heat treatment effectively en-

Figure 1 Hydrogen production during anaerobic fermentation by the pretreated seed sludge. (a)APSS cultivated in SAPS; (b) APSS cultivated in SHPS; (c)HPSS cultivated in SAPS; (d)HPSS cultivated in SHPS. 
riched acidophilic hydrogen-producing bacteria and killed hydrogen-consuming bacteria, while alkali treatment enriched basophilic hydrogen-producing bacteria but did not effectively kill hydrogen-consuming bacteria, and the strong alkali $\mathrm{pH}$ condition was favorable for inhibiting the activity of hydrogen-consuming bacteria.

It is well known that sewage sludge is very rich in anaerobes and has been used as an inoculant for biohydrogen fermentation by many authors [36-38]. In this study, high hydrogen production of APSS appeared at $\mathrm{pH} 11$ using

Table 2 Kinetic parameters of hydrogen production by the pretreated seed sludge ${ }^{\text {a) }}$

\begin{tabular}{|c|c|c|c|c|c|c|c|}
\hline \multirow{2}{*}{ Seeds } & \multirow{2}{*}{ Initial $\mathrm{pH}$} & \multicolumn{3}{|c|}{ SHPS } & \multicolumn{3}{|c|}{ SAPS } \\
\hline & & $\lambda(\mathrm{h})$ & $R_{m}(\mathrm{~mL} / \mathrm{h}$ g-COD $)$ & $H_{\max }(\mathrm{mL} / \mathrm{g}-\mathrm{COD})$ & $\lambda(\mathrm{h})$ & $R_{m}(\mathrm{~mL} / \mathrm{h} \mathrm{g}-\mathrm{COD})$ & $H_{\max }(\mathrm{mL} / \mathrm{g}-\mathrm{COD})$ \\
\hline \multirow{5}{*}{ HPSS } & 10 & $>300$ & - & - & $>300$ & - & - \\
\hline & 9 & 120 & 0.08 & 1.58 & 129 & 0.05 & 1.18 \\
\hline & 8 & 48 & 0.23 & 2.21 & 51 & 0.21 & 1.89 \\
\hline & 6 & 59 & 0.64 & 7.96 & 63 & 0.46 & 5.61 \\
\hline & 5 & 80 & 0.80 & 8.94 & 91 & 0.59 & 6.45 \\
\hline \multirow{6}{*}{ APSS } & 11 & 31 & 0.11 & 4.85 & 34 & 0.86 & 10.32 \\
\hline & 10 & 18 & 0.11 & 4.67 & 19 & 0.89 & 8.26 \\
\hline & 9 & 11 & 0.13 & 4.40 & 13 & 0.50 & 4.58 \\
\hline & 8 & 5 & 0.22 & 3.68 & 6 & 0.32 & 4.13 \\
\hline & 6 & 4.5 & 0.37 & 3.77 & 4 & 0.33 & 3.49 \\
\hline & 5 & 15 & 0.44 & 5.66 & 16 & 0.37 & 4.40 \\
\hline
\end{tabular}

a): SAPS, Supernate of alkali pretreated sludge; SHPS, supernate of heat pretreated sludge; APSS, alkali pretreated seed sludge; HPSS, heat pretreated seed sludge
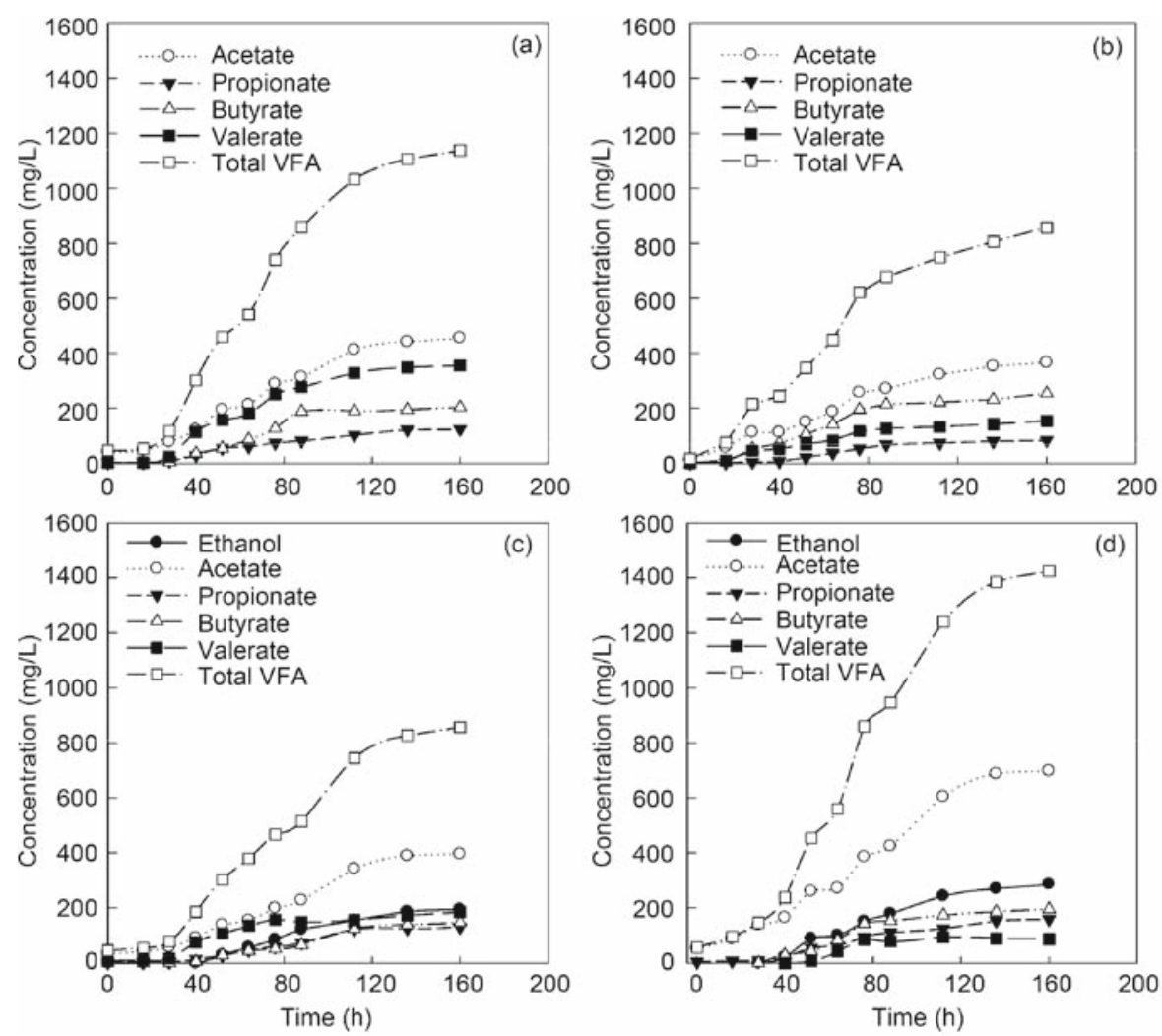

Figure 2 VFA and ethanol production during hydrogen production from the supernate of the pretreated sludge by the pretreated seed sludge. (a) APSS cultivated in SAPS (initial pH 11); (b)APSS cultivated in SHPS (initial pH 5); (c)HPSS cultivated in SAPS (initial pH 5); (d) HPSS cultivated in SHPS (initial $\mathrm{pH}$ 5). 
SAPS as the substrate and $\mathrm{pH} 5$ using SHPS as the substrate, respectively (Table 2). This indicated that there were at least two types of hydrogen-producing bacteria in the alkali treated sludge: acidophilic hydrogen-producing bacteria and basophilic hydrogen-producing bacteria. Comparing the hydrogen production of APSS with that of HPSS, it can be concluded that HPSS could not produce hydrogen gas under strong alkali conditions due to the sensitivity of basophilic hydrogen-producing bacteria to the heat treatment. This suggestion is consistent with data in the literature, since almost all hydrogen production in the literature by HPSS was obtained under acidic $\mathrm{pH}$ conditions[39].

Figure 2 summarizes the VFA and ethanol production of several representative groups during hydrogen production from the supernate of pretreated sludge. The representative groups selected in this study include APSS cultivated in SAPS (initial pH 11), APSS cultivated in SHPS (initial $\mathrm{pH}$ 5), HPSS cultivated in SAPS (initial $\mathrm{pH}$ 5), and HPSS cultivated in SHPS (initial $\mathrm{pH}$ 5). In each case, hydrogen production was relatively high under each specific condition. As shown in Figure 2, the composition of VFAs in the four groups was the same, all consisted of acetate, propionate, butyrate and valerate, and acetate was dominant. At the end of fermentation, the concentration of total VFAs in the four groups increased to 1137.1, 856.8, 856.6 and 1423.9 $\mathrm{mg} / \mathrm{L}$, respectively, and the fraction of acetate, propionate, butyrate and valerate in the four groups ranged from $40 \%-49 \%, 10 \%-15 \%, 14 \%-30 \%$ and $6 \%-31 \%$, respectively. These results are different from those of hydrogen production from carbohydrate by heat or alkali pretreated seed sludge $[13,18,19]$ and those from heat pretreated sludge by pure culture [11], in which VFAs mainly consisted of butyrate and acetate; but are similar to hydrogen production from the self-fermentation of pretreated sludge $[21,22]$. Due to the complicated substrate and microbial community, the pathway of hydrogen production from the self-fermentation of pretreated sludge was more complicated than that from carbohydrate $[13,18,19]$ and by that of pure bacteria [11].

Comparing the VFA production in the alkali condition (Figure 2(a)) with that in the acidic condition (Figure 2(b)-(d)), it was found that the concentration of valerate in the alkali condition was higher than that in the other three groups, indicating that the pathway of hydrogen production under alkali conditions was different from that under acidic conditions. Comparing the soluble metabolites produced by APSS with that by HPSS, it was found that no ethanol was produced by APSS but was produced by HPSS, implying that the pathway of hydrogen production by APSS might be different from that by HPSS. The above results suggest that the substrate, culture condition and seed can affect the fermentation pathway.

In order to investigate the differences in the microbial communities enriched with heat pretreatment and alkali pretreatment, three representative groups were subjected to
PCR-DGGE analysis. The representative groups included HPSS cultivated in SAPS (initial pH 5), APSS cultivated in SAPS (initial $\mathrm{pH}$ 5), and APSS cultivated in SAPS (initial $\mathrm{pH} 11$ ). The sampling time was at the end of biogas generation. The DGGE profile and the cluster analysis are shown in Figure 3. As the DGGE profile shows, although lane 1 (HPSS cultivated in SAPS, initial pH 5) and lane 2 (APSS cultivated in SAPS, initial $\mathrm{pH}$ 5) shared the same substrate and the same initial $\mathrm{pH}$ condition, the number of bands in lane 1 was much less than that in lane 2 (Figure 3), suggesting that the species diversity of HPSS was less than that of APSS. In addition, the cluster analysis showed that lane 1 and lane 2 were located in one cluster due to their similarity (Dice coefficient, 57\%). These results indicate that some sludge bacteria can not only be screened by heat pretreatment but also by alkali pretreatment, and heat pretreatment has a stronger lethal effect than alkali pretreatment on the

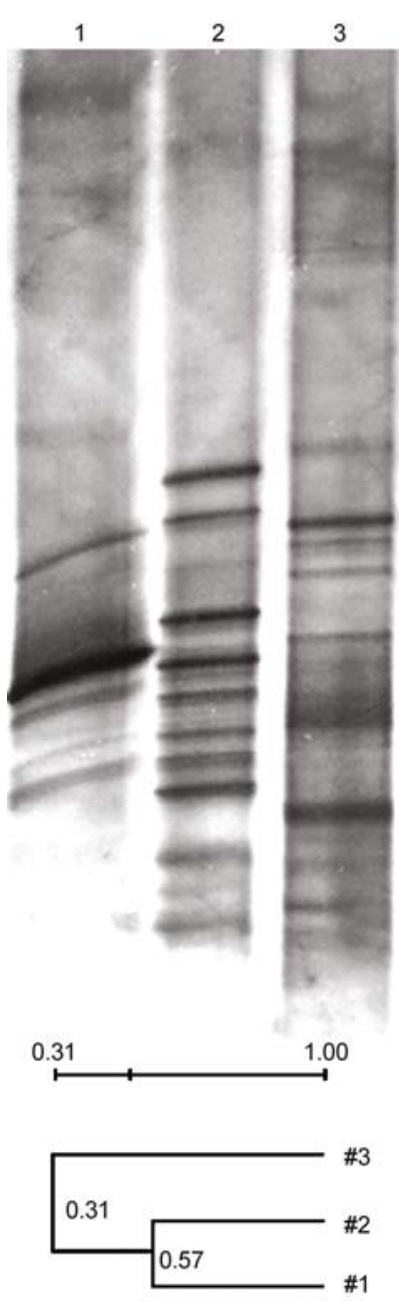

Figure 3 Comparison of the microbial communities enriched with heat and alkali pretreatment. Lane 1 to lane 3 were taken at the end of the experiment when biogas generation had stopped. The up side shows the DGGE profiles of the microbial community, and the down side gives the cluster analysis of the DGGE profile using the complete linkage method. Lane 1, HPSS cultivated in SAPS (initial pH 5); lane 2, APSS cultivated in SAPS (initial pH 5); lane 3, APSS cultivated in SAPS (initial pH 11). 
sludge bacteria. However, although having the same seed and substrate, the number of bands in lane 2 was more than that in lane 3 (APSS cultivated in SAPS, initial $\mathrm{pH} 11$ ), and the Dice coefficient for lane 2 and lane 3 was only $31 \%$. This result implies that the higher hydrogen production from SAPS by APSS at strong alkali initial $\mathrm{pH}$ compared with that at near neutral initial $\mathrm{pH}$ may be due to the fact that the former can effectively inhibit hydrogen-consuming bacteria and the latter can not inhibit these bacteria. Since the microbial communities in the treated sludge are very complicated, and a lot of anaerobic bacteria are present in addition to many aerobic bacteria and some dead bacteria, the differences in the microbial community of APSS and HPSS still require further study.

\subsection{Second batch tests with the peptone or glucose me- dium}

The above study revealed that the maximum hydrogen production of APSS was obtained from SAPS at an initial $\mathrm{pH}$ of 11; while the maximum hydrogen production of HPSS was obtained from SHPS at an initial $\mathrm{pH}$ of 5 . In order to investigate the differences in using an organic substrate by the former microbial community (tentatively called alkali -culture in this study) and by the latter (tentatively called acidic-culture in this study), the two cultures were inoculated into peptone or glucose medium, respectively, to assess hydrogen production. The initial $\mathrm{pH}$ in the alkali-culture and the acidic-culture was set to 10.5 and 5.5, respectively, to shorten the lag phase.

The hydrogen production from peptone or glucose is shown in Figure 4. The results showed that no hydrogen gas was produced after the alkali-culture was inoculated into glucose medium (Figure 4, line A), suggesting that glucose was not suitable for hydrogen production under strong alkali conditions. As we know, the anaerobic fermentation of carbohydrate always leads to a significant decrease in medium $\mathrm{pH}$, which consequently results in the inactivity of hydrogen-producing bacteria. In this study, during hydrogen production from glucose or SHPS under alkali conditions, a sharp drop in $\mathrm{pH}$ was observed (data not shown). Comparing the proportion of carbohydrate of SHPS with that of SAPS, it was found that the former was much higher than the latter (Table 1). This may be the reason for the lower hydrogen production of APSS from SHPS under alkali conditions compared with that from SAPS.

However, when the alkali-culture was inoculated into peptone medium, a maximum cumulative hydrogen production of $18.7 \mathrm{~mL}$ was obtained (Figure 4, line B), which was similar to the hydrogen production from SAPS by APSS, indicating that protein was the main contributor to hydrogen production at alkali $\mathrm{pH}$ conditions by APSS from SAPS. These results verified the findings of Cai et al. [21], and suggested that the lower hydrogen production in alkali conditions (initial $\mathrm{pH}$ 8-11) from SHPS by APSS (Figure 1(b)) might be due to the relatively high proportion of soluble carbohydrate of SHPS (Table 1). Unlike the alkali-culture, the acidic-culture not only produced hydrogen gas from peptone but also produced hydrogen from glucose. The maximum cumulative hydrogen production from glucose was $26.6 \mathrm{~mL}$, but the maximum cumulative hydrogen production from peptone was only $2.2 \mathrm{~mL}$ (Figure 4, lines $\mathrm{C}$ and D), suggesting that it was not protein but glucose that was the main contributor to hydrogen production in weakly acidic conditions. These results demonstrated that the relatively higher hydrogen production from acidic SHPS might be due to the higher proportion of carbohydrate (Tables 1 and 2).

The soluble metabolites produced during hydrogen production from the peptone or glucose medium are shown in Figure 5. The results showed that although the seed bacteria and the initial $\mathrm{pH}$ conditions were different, the composition of soluble metabolites produced from peptone by the alkali-culture and the acidic-culture was similar: neither consisted of ethanol, but both consisted of acetate, propionate, butyrate and valerate, and acetate was dominant (Figures 5(a) and (b)). However, although the seed bacteria and the initial $\mathrm{pH}$ conditions were the same, there was a big difference in the soluble metabolites from peptone and from glucose (Figures 5(b) and (c)): only ethanol and acetate were produced from glucose. This indicated that the metabolic pathway of hydrogen production from protein and from glucose was different. The former was mixed-acid type fermentation, while the latter was ethanol-type fermentation. Comparing the soluble metabolites of the first batch test with those of the second batch, it was found that the hydrogen production in alkali conditions from SAPS by APSS was mainly from protein, while the hydrogen production in acidic conditions by HPSS was mainly from carbohydrate. The pathway of hydrogen production in acidic conditions from glucose has been investigated by numerous authors. However, the pathway of hydrogen production in alkali

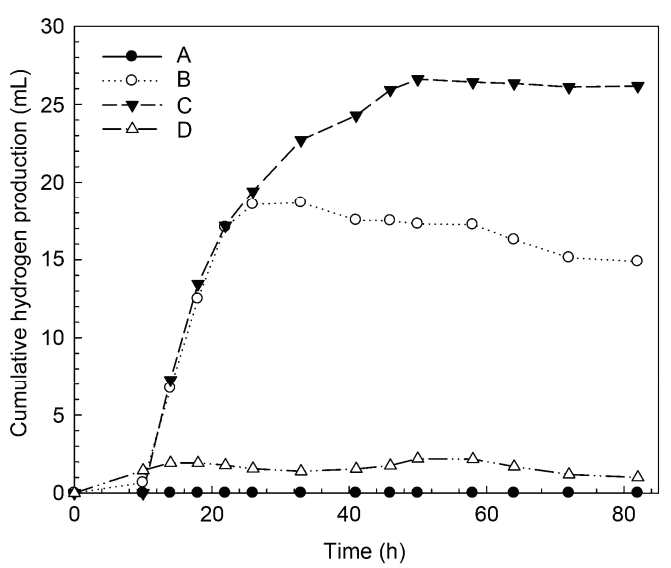

Figure 4 Hydrogen production from the artificial medium during anaerobic fermentation. A: alkali-culture cultivated in the glucose medium (initial $\mathrm{pH}$ 10.5); B: alkali-culture cultivated in the peptone medium (initial $\mathrm{pH}$ 10.5); C: acidic-culture cultivated in the glucose medium (initial $\mathrm{pH}$ 5.5); D: acidic-culture cultivated in the peptone medium (initial $\mathrm{pH} 5.5$ ). 

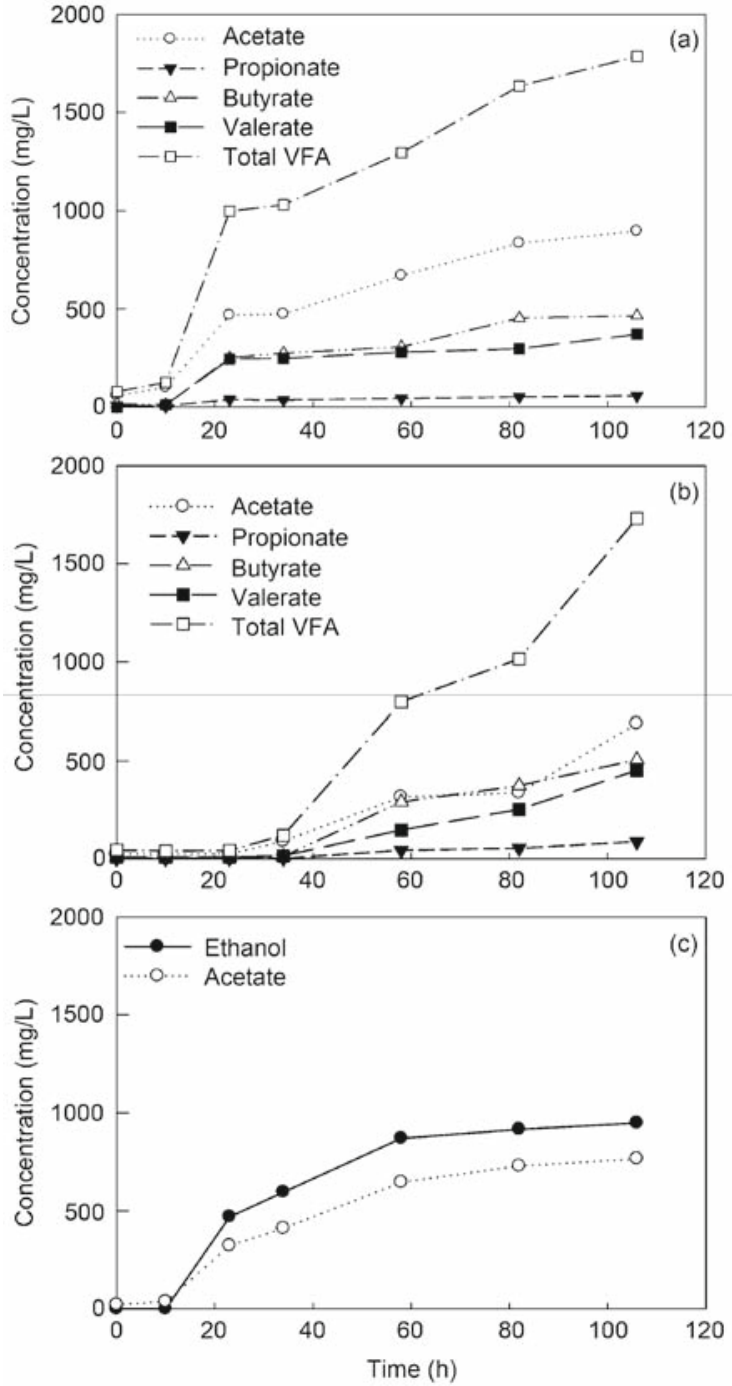

Figure 5 VFA and ethanol production during hydrogen production from the artificial medium. (a) Alkali-culture cultivated in the peptone medium (initial $\mathrm{pH} 10.5)$;(b)acidic-culture cultivated in the peptone medium (initial $\mathrm{pH} 5.5) ;(\mathrm{c})$ acidic-culture cultivated in the glucose medium (initial $\mathrm{pH}$ $5.5)$.

conditions from protein still requires further elucidation.

The shifts in the microbial community of the acidic-culture from SHPS to peptone or glucose and the alkali-culture from SAPS to peptone are shown in Figure 6 and Figure 7,respectively. As Figure 6 shows, the Dice coefficient for the microbial community of SHPS-utilizing and glucose- utilizing, and SHPS-utilizing and peptone-utilizing were $52.8 \%$ and $17.9 \%$, respectively. The former was much higher than the latter, suggesting that glucose-utilizing bacteria were dominant in the acidic-culture. The Dice coefficient for the microbial community of SAPS-utilizing and peptone-utilizing was as high as $53.3 \%$, indicating that protein-utilizing bacteria were dominant in the alkali-culture (Figure 7). The factors influencing the changes in the microbial community are multiple and include the substrate, the cultivation conditions and the seed bacteria. In this study, all the fermentation conditions were the same and the seed bacteria were from the last generation, therefore the substrate was the main factor in determining the shift in the microbial community of the acidic-culture and alkali-culture. Compared with SHPS or SAPS, nutrition in the peptone and the glucose medium was very poor. It is well known that some bacteria can not utilize peptone or glucose alone, and some bacteria need growth factors to ensure growth. Therefore, after the acidic-culture and alkali-culture were transferred into the peptone or glucose medium, the diversity of the microbial community was decreased. Although the diversity of the microbial community decreased, the above results implied that the hydrogen production by HPSS from SHPS in weakly acidic conditions mainly depended on the activity of glucose-utilizing bacteria, and the hydrogen production by APSS from SAPS in alkali conditions mainly depended on the activity of protein-utilizing bacteria.

\section{Conclusions}

This work investigated the effects of alkali and heat pre-
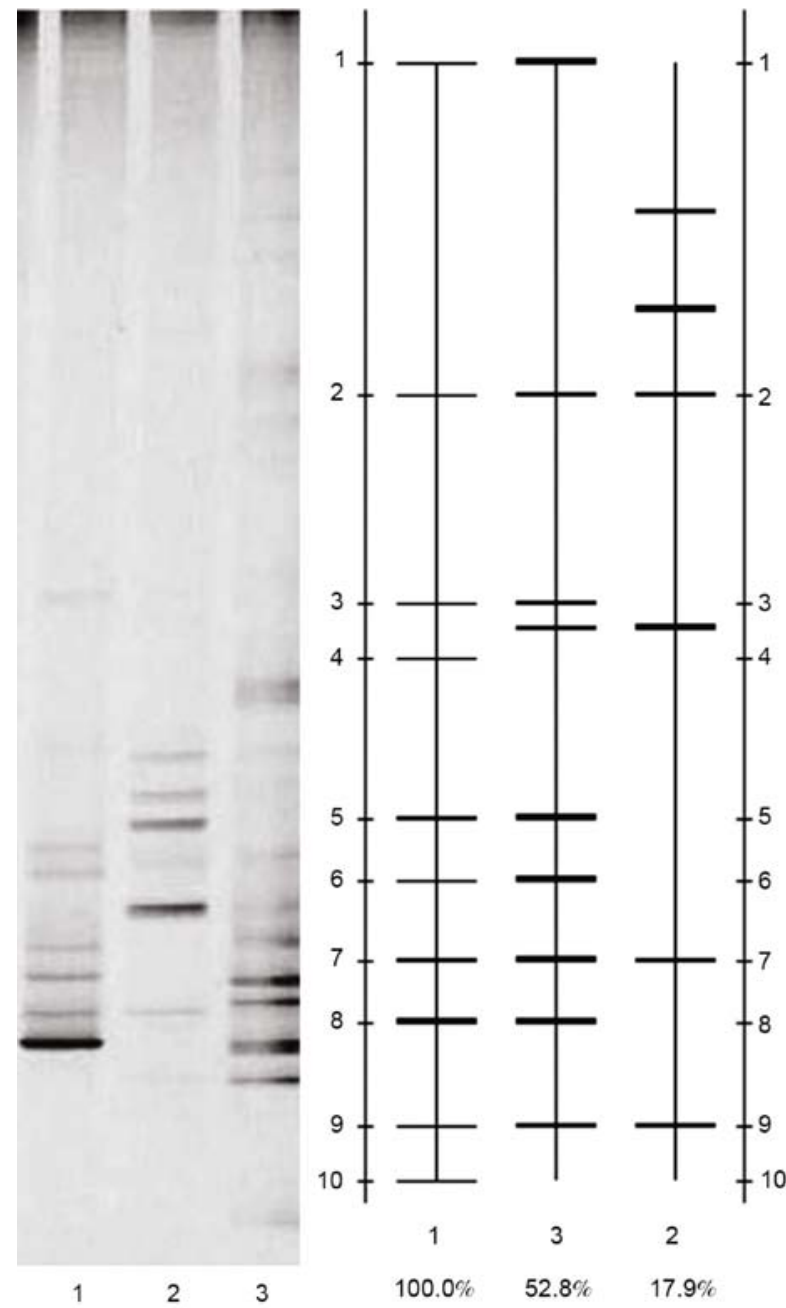

Figure 6 The shifts in the microbial community of the acidic-culture from SHPS to peptone or glucose. Lanes 1 to 3 were taken at the end of the experiment when biogas generation had stopped. The left side shows the DGGE profiles of the microbial community, and the right side gives the analysis results of lane comparison from the DGGE profile using Quantity One 4.6.2 software. Lane 1, SHPS (initial pH 5); lane 2, the peptone medium (initial pH 5.5); lane 3, the glucose medium (initial pH 5.5). 

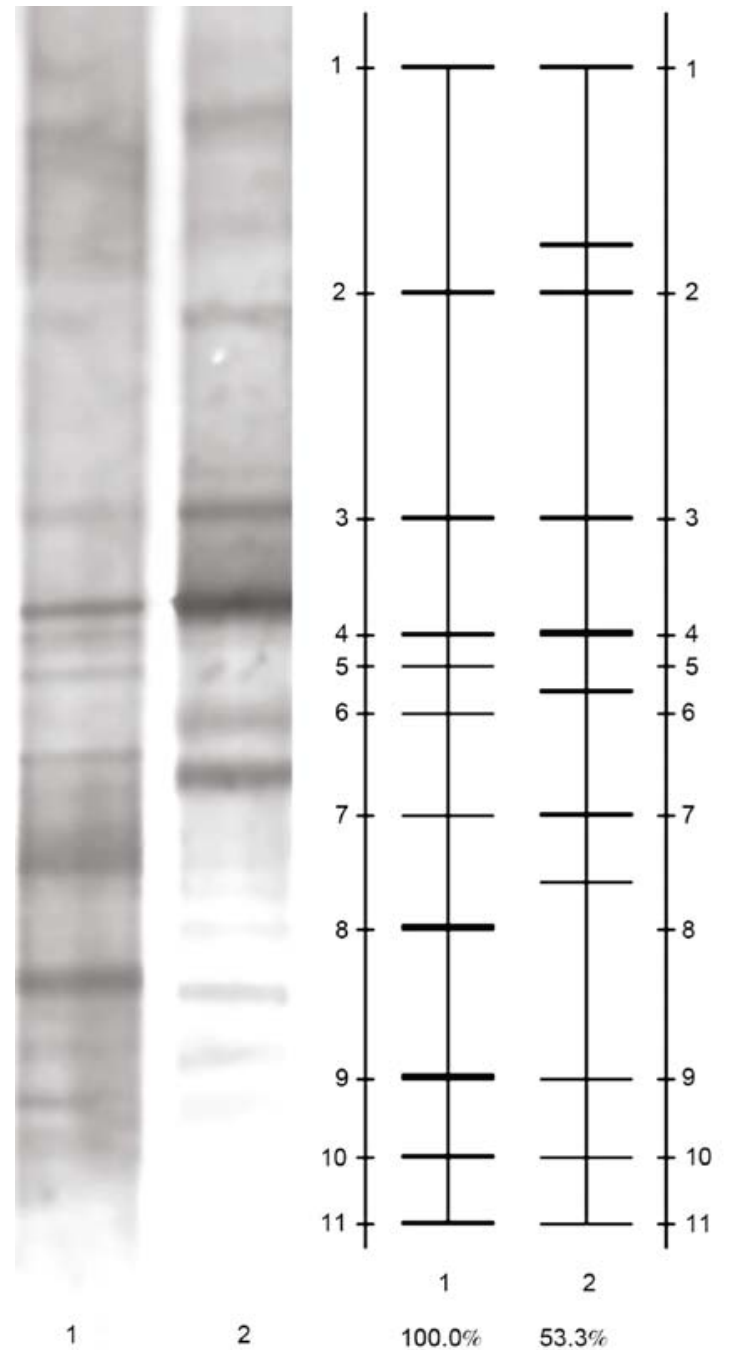

Figure 7 The shift in the microbial community of the alkali-culture from SAPS to peptone. Lanes 1 to lane 3 were taken at the end of the experiment when biogas generation had stopped. The left side shows the DGGE profiles of the microbial community, and the right side gives the analysis results of lane comparison from the DGGE profile using Quantity One 4.6.2 software. Lane 1, SAPS (initial pH 11); lane 2, the peptone medium (initial $\mathrm{pH}$ 10.5).

treatment on the pathway of hydrogen production from sewage sludge. The results showed that heat pretreatment was different from alkali pretreatment in both releasing soluble organics and screening hydrogen-producing bacteria. Heat treatment had a much stronger lethal effect on bacteria than alkali treatment, and could effectively kill hydrogen-consuming bacteria, but alkali treatment could not. Heat treatment was more suitable for enriching acidophilic hydrogen-producing bacteria, while alkali treatment was more suitable for enriching basophilic hydrogen-producing bacteria. In acidic conditions, SHPS was more suitable for hydrogen production than SAPS, while in alkali conditions $(\mathrm{pH}>9)$, SAPS was more suitable for hydrogen production than SHPS. Analysis of the pathway of hydrogen production showed that hydrogen production in acidic conditions from SHPS by HPSS mainly depended on glucose-utilizing bacteria fermenting carbohydrate by producing ethanol, whereas hydrogen production in alkali conditions $(\mathrm{pH}>9)$ from SAPS by APSS mainly depended on protein-utilizing bacteria fermenting protein by producing mixed acid.

This work was supported by the National Natural Science Foundation of China (Grant No. 50621804).

1 Appels L, Baeyens J, Degreve J, et al. Principles and potential of the anaerobic digestion of waste-activated sludge. Prog Energy Combust Sci, 2008, 34: 755-781

2 Gujer W, Zehnder A J B. Conversion processes in anaerobic-digestion. Water Sci Technol, 1983, 15: 127-167

3 Spyros G. Pavlostathis J M G. A kinetic model for anaerobic digestion of biological sludge. Biotechnol Bioeng, 1986, 28: 1519-1530

4 Nah I W, Kang Y W, Hwang K Y, et al. Mechanical pretreatment of waste activated sludge for anaerobic digestion process. Water Res, 2000, 34: 2362-2368

5 Tiehm A, Nickel K, Zellhorn M, et al. Ultrasonic waste activated sludge disintegration for improving anaerobic stabilization. Water Res, 2001, 35: 2003-2009

6 Lin J G, Chang C N, Chang S C. Enhancement of anaerobic digestion of waste activated sludge by alkaline solubilization. Bioresour Technol, 1997, 62: 85-90

7 Bougrier C, Delgenes J P, Carrere H. Effects of thermal treatments on five different waste activated sludge samples solubilisation, physical properties and anaerobic digestion. Chem Eng J, 2008, 139: 236-244

8 Tanaka S, Kobayashi T, Kamiyama K I, et al. Effects of thermochemical pretreatment on the anaerobic digestion of waste activated sludge. Water Sci Technol, 1997, 35: 209-215

9 Kim J, Park C, Kim T H, et al. Effects of various pretreatments for enhanced anaerobic digestion with waste activated sludge. J Biosci Bioeng, 2003, 95: 271-275

10 Wang C C, Chang C W, Chu C P, et al. Producing hydrogen from wastewater sludge by Clostridium bifermentans. J Biotechnol, 2003, 102: 83-92

11 Guo L, Li X M, Bo X, et al. Impacts of sterilization, microwave and ultrasonication pretreatment on hydrogen producing using waste sludge. Bioresour Technol, 2008, 99: 3651-3658

12 Chen C C, Lin C Y, Lin M C. Acid-base enrichment enhances anaerobic hydrogen production process. Appl Microbiol Biotechnol, 2002, 58: 224-228

13 Zhu H G, Beland M. Evaluation of alternative methods of preparing hydrogen producing seeds from digested wastewater sludge. Int $\mathbf{J}$ Hydrogen Energy, 2006, 31: 1980-1988

14 Lee M J, Song J H, Hwang S J. Effects of acid pre-treatment on bio-hydrogen production and microbial communities during dark fermentation. Bioresour Technol, 2009, 100: 1491-1493

15 Cheong D Y, Hansen C L. Feasibility of hydrogen production in thermophilic mixed fermentation by natural anaerobes. Bioresour Technol, 2007, 98: 2229-2239

16 Datar R, Huang J, Maness P C, et al. Hydrogen production from the fermentation of corn stover biomass pretreated with a steam-explosion process. Int J Hydrogen Energy, 2007, 32: 932-939

17 Lu Y, Lai Q, Zhang C, et al. Characteristics of hydrogen and methane production from cornstalks by an augmented two- or three-stage anaerobic fermentation process. Bioresour Technol, 2009, 100: 2889-2895

18 Ren N Q, Guo W Q, Wang X J, et al. Effects of different pretreatment methods on fermentation types and dominant bacteria for hydrogen production. Int J Hydrogen Energy, 2008, 33: 4318-4324

$19 \mathrm{Mu} \mathrm{Y}, \mathrm{Yu} \mathrm{H}$ Q, Wang G. Evaluation of three methods for enriching $\mathrm{H}$-2-producing cultures from anaerobic sludge. Enzyme Microb 
Technol, 2007, 40: 947-953

20 Mohan S V, Babu V L, Sarma P N. Effect of various pretreatment methods on anaerobic mixed microflora to enhance biohydrogen production utilizing dairy wastewater as substrate. Bioresour Technol, 2008, 99: 59-67

21 Cai M L, Liu J X, Wei Y S. Enhanced biohydrogen production from sewage sludge with alkaline pretreatment. Environ Sci Technol, 2004, 38: 3195-3202

22 Xiao B Y, Liu J X. Biological hydrogen production from sterilized sewage sludge by anaerobic self-fermentation. J Hazard Mater, In Press, Corrected Proof.

23 Xiao B Y, Liu J X. Effects of thermally pretreated temperature on bio-hydrogen production from sewage sludge. J Environ Sci, 2006, 18: 6-12

24 Logan B E, Oh S E, Kim I S, et al. Biological hydrogen production measured in batch anaerobic respirometers. Environ Sci Technol, 2002, 36: 2530-2535

25 Liu H, Logan B E. Electricity generation using an air-cathode single chamber microbial fuel cell in the presence and absence of a proton exchange membrane. Environ Sci Technol, 2004, 38: 4040-4046

26 Lowry O H, Rosebrough N J, Farr A L, et al. Protein measurement with the Folin phenol reagent. J Biol Chem, 1951, 193: 265-275

27 Dubois M, Gilles K A, Hamilton J K, et al. Calorimetric method for determination of sugars and related substances. Anal Chem, 1956, 28 : 350-356

28 APHA. Standard methods for the examination of wastewater. 18th. Washington, D C, 1992

29 Sambrook J, Russel D W. Molecular Cloning: A Laboratory Manual. 3rd. New York: Cold Spring Harbour Laboratory Press, 2001.
30 Muyzer G, de Waal E C, Uitterlinden A G. Profiling of complex mi-crobial populations by denaturing gradient gel electrophoresis analysis of polymerase chain reaction-amplified genes coding for $16 \mathrm{~S}$ rRNA. Appl Environ Microbiol, 1993, 59: 695-700

31 Heukeshoven J, Dernick R. Simplified method for silver staining of proteins in polyacrylamide gels and the mechanism of silver staining. Electrophoresis, 1985, 6: 103-112

32 Dice L R. Measures of the amount of ecologic association between species. Ecology, 1945, 26: 297-302

33 Liu X C, Zhang Y, Yang M, et al. Analysis of bacterial community structures in two sewage treatment plants with different sludge properties and treatment performance by nested PCR-DGGE method. J Environ Sci, 2007, 19: 60-66

34 Lay J J, Lee Y J, Noike T. Feasibility of biological hydrogen production from organic fraction of municipal solid waste. Water Res, 1999, 33: 2579-2586

35 Chen C Y, Chang J S. Enhancing phototropic hydrogen production by solid-carrier assisted fermentation and internal optical-fiber illumination. Process Biochem, 2006, 41: 2041-2049

36 Zhang T, Liu H, Fang H H P. Biohydrogen production from starch in wastewater under thermophilic condition. J Environ Manage, 2003, 69: 149-156

37 Khanal S K, Chen W H, Li L, et al. Biological hydrogen production: effects of $\mathrm{pH}$ and intermediate products. Int J Hydrogen Energy, 2004, 29: $1123-1131$

38 Fang $\mathrm{H} \mathrm{H} \mathrm{P,} \mathrm{Liu} \mathrm{H}$. Effect of $\mathrm{pH}$ on hydrogen production from glucose by a mixed culture. Bioresour Technol, 2002, 82: 87-93

39 Li C L, Fang H H P. Fermentative hydrogen production from wastewater and solid wastes by mixed cultures. Crit Rev Environ Sci Technol, 2007, 37: 1-39 